\title{
A SOJA (SOJA HISPIDA, MOENCH) COMPOSIÇÃO QUÍMICA E VALOR CALÓRICO
}

(THE SOYBEAN (SOJA HISPIDA, MOFNCH) ITS CHIMICAL, COMPOSITION AND CALORIC VALUUE)

\section{Fernando Andreasi}

\author{
Assistente
}

Desde tempos imemoriais que os povos do Oriente adicionavam à alimentação comum, um vegetal de excelentes qualidades nutritivas: a soja.

Esta planta, pertencente à família das leguminosas, foi introduzida no Brasil há cêrca de 25 anos.

II. LÖßRL, um dos cntusiastas desta cultura em nosso meio, recebeu $\tilde{\jmath}$ variedades provenientes da Mandchuria, região de origem desta leguminosa e iniciou seus trabalhos de cultura no Campo de Sementes de São Simão, onde, mais tarde, introduziu mais 48 outras variedades trazidas dos Estados Unidos, aumentando assim suas observaçōes.

Trata-se de uma planta que apresenta grancles possibilidades de cultivo, c se adapta perfeitamente às nossas condições de clima. $\dot{E}$ pouco exigente com relação ao solo e oferece promissoras perspectivas à alimentação de nossos animais, dados os elevados teores de proteina e gordura das sementcs e a ótima forragem verde representada pela planta.

As plantas podem ser oferecidas aos animais sob a forma de forragem verde, de feno ou de silagem. Neste último caso, associada ao milho e introduzida em silo, constitui ótima reserva de alimento rerde para as épocas de escassez, sumamente apreciada, principalmente pelas vacas leiteiras.

As sementes integrais, que nos interessam de perto no momento, têm sido empregaras com sucesso na alimentação dos suinos, verificando-se notável desenvolvimento nos animais jovens, em virtude do alto valor biológico de sua proteína. Essta encerra todos os amino-ácidos de crescimento, podendo-se, segundo R. Gourn, assinalar, nas tortas, os seguintes valores por cem gramas: lisina 2,31; cistina 0,9 ; arginina 4,14 ; e histidina 1,47 . 
Numerosas experiências têm sido realizadas, principalmente com suinos, sendo que entre nós, J. F. BRAGA, comparando os resultados obtidos em 2 lotes de leitões, alimentados respectivamente com uma mistura de soja e fubá e de fubá e tancage, dados à vontade, não obstante o primeiro lote apresentar menor pêso em relação ao segundo, provou que a soja é um suplemento protêico de reais qualidades, mais barato e determina um crescimento mais econômico.

Quando adicionada ao milho para suprir a deficiência de proteína dêste, a soja produz resultados mais satisfatórios, além de tornar a ração muito mais econômica.

Trabalhos americanos, entretanto, aconselham não oferecer aos porcos mais de $10 \%$ de soja na ração, para evitar a depreciação da carne e possíveis distúrbios digestivos, comuns em animais novos. Estes, quando alimentados com grãos crús, apresentam dificuldades para digerí-los, o que não ocorre com os adultos.

Os efeitos produzidos quando dada sob a forma de farinha oleaginosa de soja, são realmente melhores, em virtude de um cozimento parcial sofrido pelos grãos durante a extração do óleo e talvez, também, da menor quantidade de gordura, o que facilita o ataque pelos diversos sucos digestivos, tornando-a assim, mais digestivel.

Para os eqüinos, preconisa-se administrar o feijão moído, como suplemento protêico, porém, em quantidade reduzida, por possuir as mesmas caraterísticas da farinha de linhaça. Desde que se tenha o cuidado de não dar em excesso, não há perigo de desarranjos para o lado do aparelho gastro-intestinal.

Também como suplemento protêico, a soja encerra altas qualidades para as vacas leiteiras, rivalizando com as melhores farinhas de linhaça e superando mesmo a farinha de sementes de algodão. Fornecida em quantidade adequada, constitui ótima fonte azotada, além de possuir efeito laxativo.

Os ovinos digerem bem os grãos inteiros. Parece que não há diferença, quando comparados os seus efeitos com os da farinha oleaginosa de soja.

As aves também apreciam êsse cereal, encontrando nele um elemento complementar da ração, com todos os princípios indispensáveis ao crescimento e à produção.

\section{MATERIAI}

Tendo verificado a pouca difusāo dêsse cereal em nosso meio, pois confessamos a extrema dificuldade na obtenção de amostras, nos propusemos estudar neste artigo, a composição química apenas do 
feijão soja, integral, para em trabalhos posteriores, conhecermos o seu valor biológico.

As amostras, em número de cinco, foram adquiridas em origens diversas, sem nos preocuparmos com as variedades, visto ser nosso objetivo, verificar tão sòmente a riqueza dos vários nutrientes do produto existente na praça.

Os grãos, crús, integrais, foram moídos em gral de ferro, passando-se em seguida, por uma peneira de malhas finas até a obtenção de uma farinha homogênea, representativa da amostra.

Foi inicialmente, determinada a matéria sêca, para em seguida, serem feitas as determinações dos constituintes constantes dos quadros I e II.

\section{MÉTODOS UTILIZADOS}

Anotaremos, apenas os detalhes técnicos observados para algumas determinações, uma vez que, para a maioria delas, foram adotados os métodos correntemente empregados em laboratórios.

Celulose: Foi determinada pelo processo chamado da "hidrólise rápida", adotado, oficialmente, pelo Laboratório Municipal de Santiago, o qual pela suas rapidez, reduz sensivelmente o tempo de filtração assim como dispensa o uso da glicerina, esta de custo elevado.

Acidez da farinha: Tratando-se de uma determinação, cujos resultados dependem do dissolvente escolhido, segundo as recomendações do trabalho de Sampaio MEllo, passamos a descrever na integra, o método por nós seguido.

Técnica: Pesamos e introduzimos em um matraz aferido de rolha esmerilada, de capacidade de $100 \mathrm{~cm}^{3}$, duas gramas de farinha. Em seguida, completamos o volume com álcool neutro, a 95. Após agitar o conteúdo do matraz, várias vêzes, deixamos em repouso durante 24 horas. Decorridas estas, filtramos em filtro sêco e tomamos $50 \mathrm{~cm}^{3}$ do filtrado, correspondente, portanto, a uma grama de farinha. Titulamos, finalmente, com uma solução alcalina $N / 100$, usando, como indicador, a fenolftaleina a $0,5 \%$, em solução alcoólica neutra. A acidez é expressa em ácido sulfúrico normal por cem gramas de farinha.

Ácidos gordurosos liveres: Aproveitando o extrato etéreo obtido anteriormente, fizemos a dissolução, a princípio com éter e, por último, com álcool; êstes dissolventes foram empregados após ser conhecida a sua reação. Titulamos com uma solução N/100 de hidróxido de potássio. Expressamos os resultados, em relação a cem gramas de forragem e a cem gramas de gordura. 
Calorias: Devido ao elevado teor de gordura, não nos foi possivel comprimir o material na prensa, assim como nào conseguimos resultados satisfatórios, procedendo à combustão direta, isto é, colocando o material pulverizado na cápsula interna da bomba. Removemos essa dificuldade, usando cápsulas de gelatina, cujo valor calórico foi, prèviamente determinado.

A bomba, modêlo Berthelot-IMahler, foi-nos, gentilmente cedida pelo Prof. Fonseca Ribeiro, diretor do Departamento de Química Orgânica e Biológica.

\section{COMENTÁRIOS}

Embora reduzido o número de amostras, verificámos que os teores de proteína e de gordura, em nossa análise, são sensivelmente mais elevados que os obtidos nos Estados Unidos, por WoodrufF and KlaAs e os constantes da tabela de MORIsson. Ainda, estabelecendo um confronto, com diferentes variedades oriundas dos Estados Unidos e cultivadas em nosso meio, as quiais foram analisadas na Estação Experimental de Cana e Plantas Oleaginosas de Piracicaba e cujos resultados figuram no trabalho de $H$. LöBBE, vamos verificar a riqueza dos citados elementos. F̂ste fato, aliás, foi também assinalado, em análises procedidas em Hamburgo (Alemanha), em várias varicdades de soja produzidas no Brasil.

Com relação aos carboidratos, constatam-se taxas bem reduzidas, enquanto o cálcio apresenta valores normais.

Ressalta, entretanto, a elevada porcentagem de fósforo que supera, nitidamente, os valores constantes da labela de Morisson.

\section{RESUMO}

Analisámos cinco amostras de sementes de feijão soja, de diversas procedências e, calculámos o seu valor calórico. Todos os resultados estão contidos nos quadros I e II.

$$
\text { Abstract }
$$

We have analysed five samples of soybean, from differents proveniences and determined their caloric value. All dates are in the table I and $I I$.

We huve noted that our soybean are richer in oil, motein and phosphorus then the americun soybern. 


\section{BIBLIOGRAFIA}

Braga, J. F. - 1942 - A soja moída no crecimento e na engorda de poreos. Ceres. 3 (16): $222-30$

Gous, R. - 1937 - Ie soja dans l'alimentation du beitail. Rev. Zootechnie. 7 : $36 \mathrm{i}-40$

Hansson, N. - 1944 -.. Alimentacion de los animales domesticos. 2 a ed. Madrid, Imprenata y Editorial Viuda de Juan Pueyo

LüвbL, H. - 1945 - Cultura da soja no Brasil. $7 .^{a}$ ed. Rio de Janciro, Serviço de Informaçào Agricolib

Morrison, F. B. - 1937 - Feeds and feeding. 28th ed. New York, The Morrison Publishing Comp

Ravexis, C. - 19.32 - Manuale di analisi chimica. 3. ed. Bologna, Nicola Zarnichelli

Sampalo Meio, M. - 1941 - Teores de acidêz em farinhas. Rev. Inst. Adolfo Lut $\approx$. S. Paulo, $1(2): 457-75$

Schmint-Hebres., H. - 1942 - Tratado de Bromafologia (Quimica de alimentos). Santiagro, Fditorial Nascimento

VHoLavecun, G. V. - 1937 - Trattato di Chimica analitica applicata. 2. Milano, Ulien Hoepli

WOODRUFF, S. - KhaAS, H. - 1938 - A study of soybean varicties with reference to their u:c as food. Mllinois Ayrie. Fily. Sta. Bull. $44: 3$ 
QUA D R O I

COMPOSIÇa quimica E Valor calórico

SEMENTES DE FEIJAO SOJA

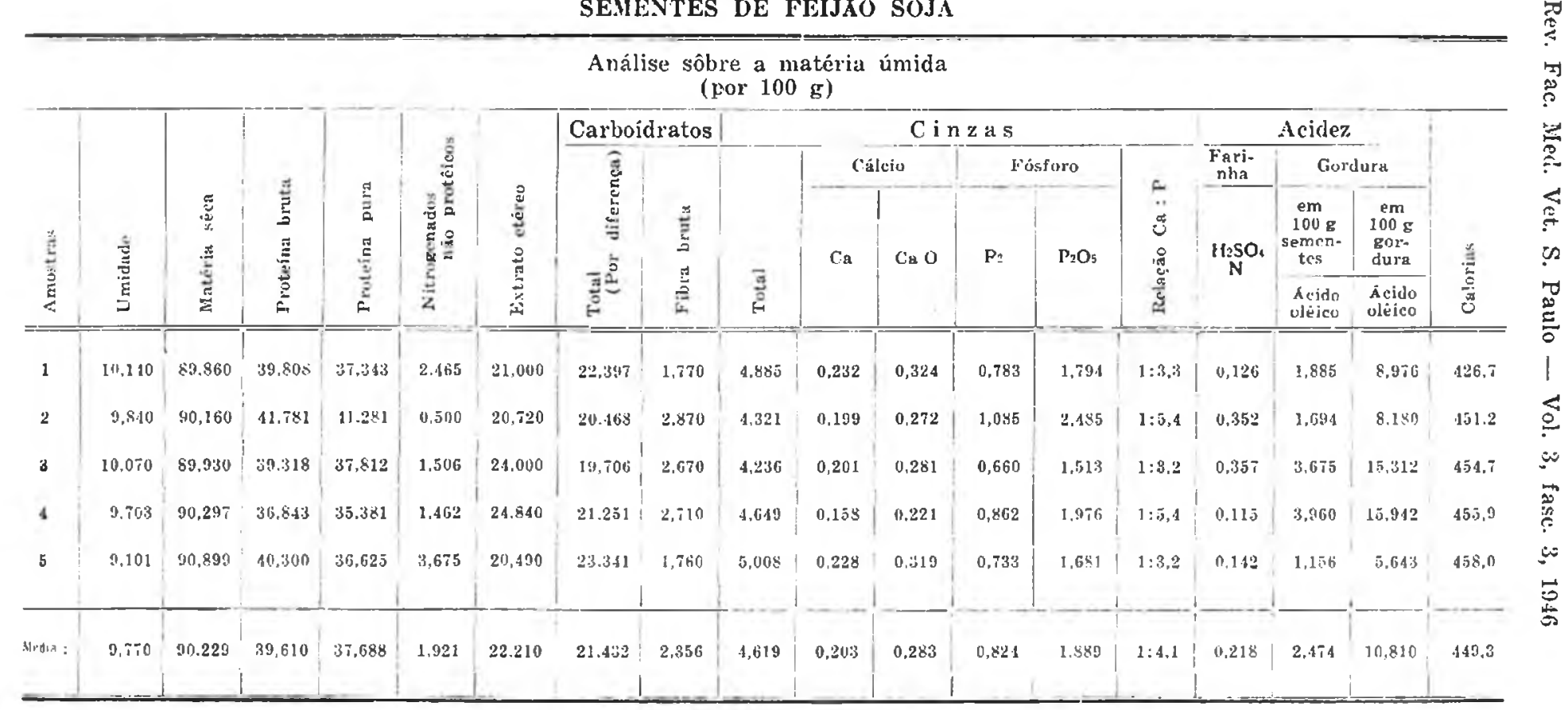

哭

20.

?

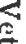

s 
QUADRO II

COMPOSIÇÃO QUTMICA E VALOR CALÓRICO

SEMENTES DE FEIJAO SOJA

\begin{tabular}{|c|c|c|c|c|c|c|c|c|c|c|c|c|c|c|c|c|c|c|}
\hline \multirow{5}{*}{ 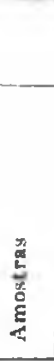 } & \multicolumn{18}{|c|}{$\begin{array}{c}\text { Análise sôbre matéria isenta de umidade } \\
\text { (Eor } 100 \mathrm{~g} \text { ) }\end{array}$} \\
\hline & \multirow{4}{*}{ 递 } & \multirow{4}{*}{ 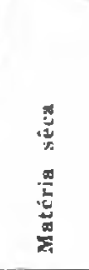 } & \multirow{4}{*}{ 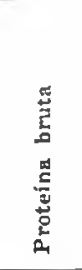 } & \multirow{4}{*}{ 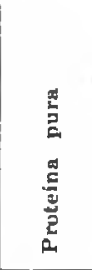 } & \multirow{4}{*}{ 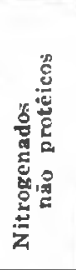 } & \multirow{4}{*}{ 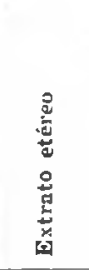 } & \multicolumn{2}{|c|}{ Carboidratos } & \multicolumn{6}{|c|}{$\mathrm{Cinzas}$} & \multicolumn{3}{|c|}{ Acidez } & \multirow{4}{*}{ 量 } \\
\hline & & & & & & & \multirow{3}{*}{ 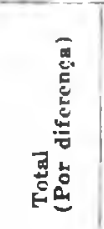 } & \multirow{3}{*}{ 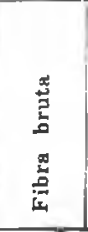 } & \multirow[b]{3}{*}{$\sum_{5}^{5}$} & \multicolumn{2}{|c|}{ Cálecio } & \multicolumn{2}{|c|}{ Fúxforo } & \multirow{3}{*}{ 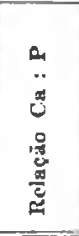 } & \multirow{3}{*}{$\begin{array}{c}\begin{array}{c}\text { Fari- } \\
\text { nha }\end{array} \\
\\
\mathrm{H}_{\mathrm{N}}^{\mathrm{H} \mathrm{SO}_{4}}\end{array}$} & \multicolumn{2}{|c|}{ Gordura } & \\
\hline & & & & & & & & & & \multirow[t]{2}{*}{$C A$} & \multirow[t]{2}{*}{$\mathrm{CaO}$} & \multirow[t]{2}{*}{$\mathbf{P}_{2}$} & \multirow[t]{2}{*}{$\mathrm{P}_{2} \mathrm{O}_{5}$} & & & $\begin{array}{c}\mathrm{em} \\
100 \mathrm{z} \\
\text { semen- } \\
\text { tes }\end{array}$ & $\begin{array}{c}\mathrm{cm} \\
100 \\
\text { kor- } \\
\text { durg }\end{array}$ & \\
\hline & & & & & & & & & & & & & & & & $\begin{array}{l}\text { Acido } \\
\text { olêico } \\
\end{array}$ & $\begin{array}{c}\text { Acido } \\
\text { olêico }\end{array}$ & \\
\hline 1 & - & 50,860 & 44,300 & 41,550 & 2,743 & 23,369 & 24.924 & 1,969 & 5,436 & 0.258 & 0.860 & 0.871 & 1,996 & $1: 3,3$ & 0,140 & 2.097 & 9.388 & 474.9 \\
\hline 2 & - & 90,160 & 46,341 & 45,786 & $0, \overline{554}$ & 22,981 & 22,701 & 3,183 & 4.792 & 0,220 & 0,301 & 1.203 & 2,756 & $1: 5,4$ & 0,390 & 1,878 & 9.072 & 500,5 \\
\hline 3 & - & 89,930 & 43,721 & 42,046 & 1,674 & 26,687 & 21.912 & 2,968 & 4.710 & 0,223 & 0.312 & 0.834 & 1,682 & $1: 3,2$ & 0,396 & 4.086 & 17,026 & 505,7 \\
\hline 4 & - & 90,297 & 40.805 & 39,182 & 3,619 & 27,509 & 23.538 & 3,001 & 5.148 & 0.174 & 0,244 & 0,955 & 2.188 & $1: 5,4$ & 0.127 & 4,385 & 17.655 & 505.0 \\
\hline 5 & - & 90,899 & 44.334 & 40,291 & 4,042 & 22,641 & 25,677 & 1,936 & 6,509 & 0.250 & 0,350 & 0.807 & 1.849 & $1: 3,2$ & 0.156 & 1,271 & 6,207 & 603,9 \\
\hline Metia : & - & 90,229 & 43,900 & $11, \pi 72$ & 2,126 & 24,617 & 23,750 & 2,611 & 5,119 & 0.225 & 0,313 & 0.914 & 2,091 & $1: 4,1$ & 0.241 & 2,743 & 11.989 & 498,0 \\
\hline
\end{tabular}

